\title{
ARQUITETURAS PEDAGÓGICAS PARA A APRENDIZAGEM EM REDE NO CONTEXTO DO SEMINÁRIO INTEGRADOR
}

\author{
Crediné Silva de Menezes, FACED - UFRGS, \\ credine@gmail.com \\ Rosane Aragón, FACED - UFRGS, \\ rosane.aragon@ufrgs.br \\ Mariangela Lenz Ziede, PPGEDU - UFRGS, \\ marianzelaziede@gmail.com \\ Simone Bicca Charczuk, UNISINOS, \\ sibicca@gmail.com
}

\begin{abstract}
Resumo: Aprender em rede requer, além da disponibilidade dos recursos, um interesse dos participantes na realização de diálogos descentrados, buscando a coordenação dos diversos pontos de vista com o objetivo de fazer emergir um nível mais qualificado de compreensão da temática em debate. A mera disponibilidade da tecnologia, por mais sofisticada que seja não basta. É fundamental que se estabeleça uma política de participação e que o grupo tenha interesse na avaliação cooperativa. Neste sentido, no desenvolvimento do Curso de Graduação - Licenciatura em Pedagogia na modalidade a distância e, mais especificamente, na interdisciplina Seminário Integrador, voltada para a formação do professor-pesquisador, usamos o conceito de arquiteturas pedagógicas para o desenvolvimento de propostas inovadoras com ênfase na aprendizagem em rede. Três destas propostas são apresentadas em conjuntos com as discussões sobre seus usos.
\end{abstract}

Palavras-chave: Inovação Pedagógica, TDIC aplicada à Educação, Arquitetura Pedagógica, Educação a Distância, Aprendizagem em Rede.

\section{PEDAGOGICAL ARCHITECTURES FOR THE LEARNING IN NETWORK AT THE "SEMINARIO INTEGRADOR" CONTEXT}

\begin{abstract}
Besides the resources availability, learning in a network requires the participant's interest in the realization of the decentered dialogues, looking for the coordination of different point of views with the goal to emerge one more qualified level of the comprehension of the thematic in discussion. It is not enough to just have the technology available even with it's sophistication. It is essential that a political establishment of participation be established and that the group has interest in the cooperative evaluation. In this sense, at the development of the graduation course licensure in pedagogy at the distance educational mode, more precisely at the "Seminário Integrador" interdiscipline, focused for the professor-researcher formation, we used the pedagogical architectures concept for the development of innovative researches with the emphasis at the network learning. Three of these proposals are presented in conjunct with the discussion about it's uses.
\end{abstract}


Key words: pedagogical innovation, ICT applied into education, pedagogic architecture, distance education, network learning. 


\section{Introdução}

A oferta de recursos de autoria, publicação e interação ao alcance de todos (que possuam acesso à internet) coloca à disposição dos educadores uma oportunidade ímpar de promover uma inovação em educação. Essas inovações deverão romper de forma contundente com as velhas práticas instrucionistas, demarcadas principalmente pela lógica das aulas transmissivas, realizadas entre quatro paredes, constituindo-se em um espaço privado de interlocução entre um professor e seus alunos, distanciado do contexto dos indivíduos e demarcado por um modelo de consumo das informações proveniente do meio externo.

A situação típica de sala de aula, notadamente no ensino fundamental, nos dias atuais é a de um professor apresentando aos seus alunos um conteúdo previamente definido em livros didáticos, seguido de atividades individuais que são registradas nos cadernos particulares. O acesso do professor e dos colegas a essas produções é restrito, pela natureza do suporte, e dificulta a realização de atividades cooperativas. Quando muito, o que se verifica é a realização de trabalhos em equipes, que também são dificultados no processo de produção e principalmente na socialização. Com isto, a aprendizagem cooperativa é pouco explorada nas escolas. No modelo vigente, também a avaliação fica restrita aos produtos finais, sem que o processo de construção do conhecimento seja registrado e acompanhado, repetindo-se o paradigma contestado por Paulo Freire (1999), ao qual denominou de Educação Bancária.

Em contraposição ao modelo bancário, no qual o sujeito memoriza e repete o conhecimento que lhe foi transmitido, temos o modelo relacional (Becker, 2001) que propicia ao aluno a construção de novos conhecimentos. Estudos da Psicologia Genética (Piaget, 1973) apontam para a necessidade das interações dos sujeitos com o meio ambiente, destacando-se as interações com outros sujeitos, para a promoção da aprendizagem. Nesta concepção, os indivíduos constroem conhecimento a partir de suas experiências e reflexões. Para tal, faz-se necessário a oferta de propostas pedagógicas apropriadas. Assim, não basta dizer aos alunos que interajam e aprendam! É necessário criar as oportunidades, dar-lhes os meios e, além disso, propiciar a mediação.

Sem as ferramentas apropriadas à publicação e à produção cooperativa, as dificuldades de criar propostas pedagógicas ampliando a participação coletiva são inúmeras e por certo contribuem de forma marcante para que novas concepções pedagógicas não tenham oportunidade de serem experimentadas.

Preparar os professores para vivenciarem uma experiência de aprendizagem em um ambiente inovador de produção de conhecimento foi um dos principais aspectos que nortearam a realização do Curso de Graduação - Licenciatura em Pedagogia na modalidade a distância (PEAD), levando em conta todas as modalidades de comunicação e interação disponíveis, o que nos levou a explorar o uso de ambientes e ferramentas o mais flexível e acessível possível. Nossa meta era, além de propiciar que nosso aluno experimentasse essas novas oportunidades na sua formação, dar-lhe condições para que tivesse a facilidade de realizar transposições didáticas, ou seja, que pudesse estender essa aprendizagem para a sua prática pedagógica.

Neste artigo apresentamos as ideias que nortearam a elaboração de propostas pedagógicas no PEAD, voltadas para construção de conhecimento, incluindo as oportunidades de mediação. Apresentamos alguns exemplos de atividades realizadas pelos alunos, no contexto da interdisciplina Seminário Integrador, considerando o conceito de Arquiteturas Pedagógicas, bem como descrevemos estratégias e ferramentas utilizadas na mediação e, por fim, fazemos algumas reflexões sobre os resultados desta abordagem. 


\section{Uma breve apresentação do curso}

O Curso foi desenvolvido em nove eixos temáticos, com cada eixo correspondendo a um semestre letivo. Cada eixo contemplou um grande tema norteador, orientando um planejamento integrado em cada um dos semestres, com a intenção de oferecer atividades que possibilitassem o estudo de um mesmo fenômeno sobre diferentes olhares, em diferentes interdisciplinas. O ponto de apoio dessa articulação foi 0 Seminário Integrador, que, além de coordenar o planejamento integrado, teve como responsabilidade a realização de atividades voltadas para a formação metodológica do aluno, na perspectiva de formação do professor-pesquisador.

O curso foi realizado na modalidade a distância, com encontros presenciais periódicos, para apresentação do plano de cada eixo, realização de atividades específicas das interdisciplinas, workshop de avaliação e alguns encontros de replanejamento. As atividades principais do curso foram realizadas e mediadas à distância, usando diversos ambientes virtuais e ferramentas de comunicação.

As propostas de trabalhos foram inteiramente veiculadas pela web assim como a realização de atividades, individuais e cooperativas, e a constante mediação realizada por tutores e professores, na modalidade síncrona e assíncrona.

O corpo docente foi formado por professores e tutores, organizados em equipes por polo e por interdisciplinas, interpolos. Os professores realizavam, além do habitual papel de coordenação das interdisciplinas, produção de materiais e orientação ao corpo de tutores, atividades de mediação direta junto aos alunos.

Na Figura 1 apresentamos o esquema típico da rede docente para a realização de uma interdisciplina do curso. Cada interdisciplina contou com um quadro de cinco professores por interdisciplina, na qual cada professor era responsável por um polo e um destes docentes era o coordenador da interdisciplina. Este coordenador era responsável pela equipe junto à coordenação do curso. Por vezes, reunia-se com o grupo de professores e tutores para discutir estratégias de atuação, revisão e modificação dos materiais, caso fosse necessário.

Figura 1: Desenho da equipe docente para uma interdisciplina.

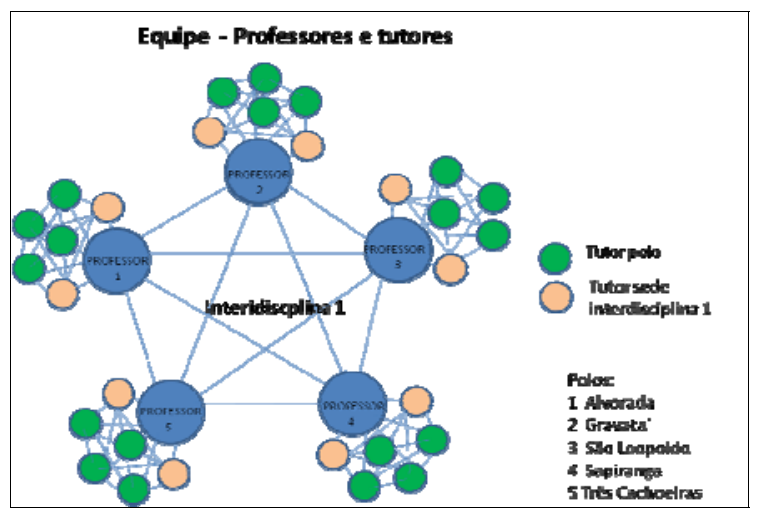

Fonte: Elaborada pelos autores.

Por se tratar de uma formação em serviço, o curso teve por princípio o desenvolvimento de suas ações pedagógicas articuladas com o trabalho do aluno, a partir da concepção de atividades que, partindo das suas práticas de suas salas de aula, fossem ressignificadas, estabelecendo assim um diálogo qualificado entre o conhecimento teórico e suas práticas pedagógicas. 
A avaliação das aprendizagens foi realizada de forma processual, tendo por base o desenvolvimento das atividades interdisciplinares pelos alunos, a produção de narrativas individuais durante o desenvolvimento de cada eixo e a produção textual ao final de cada semestre, que eram apresentadas oralmente em um workshop de avaliação, para uma comissão de avaliação geralmente composta por professores e tutores que atuaram no eixo.

\subsection{A Interdisciplina Seminário Integrador}

A interdisciplina Seminário Integrador (SI), foi concebida para se desenvolver ao longo de todo o curso, caracterizando-se pela flexibilização programática, diferenciada a cada eixo de acordo com as necessidades das demais interdisciplinas. Um de seus papéis fundamentais é apoiar a integração intra-eixo e, ao mesmo tempo, inter-eixos. As atividades do SI se concentraram no desenvolvimento da iniciação à pesquisa e no aporte de metodologias para apoiar e integrar o trabalho pedagógico em cada eixo.

Uma das atividades centrais dos Seminários foi o acompanhamento do processo avaliativo, realizado de forma processual, tendo por base um portfólio de aprendizagens acompanhado de forma intensiva e continuada pelos professores e tutores do SI. O portfólio foi construído desde os primeiros semestres do curso e ao final de cada semestre deu suporte à produção de trabalhos para o Workshop de Avaliação.

Em razão da sua função articuladora e integradora, os docentes, salvo algumas exceções, foram os mesmos desde o início até o final do curso. Ou seja, para cada polo havia dois professores que participam do desenvolvimento do curso em todos os seus nove eixos e conheciam singularmente os alunos e a sistemática do polo.

\section{Aprendizagem em Rede}

No modelo convencional de ensino, a comunicação se dá, predominantemente, de forma unidirecional, as mensagens tem como emissor o professor e como receptor os alunos. Tendo em vista a sobrecarga de aulas, o tempo dos professores é exíguo, o que implica na inexistência de momentos para os diálogos entre professores e alunos.

Entre as abordagens alternativas para o trabalho coletivo, destacam-se os encontros na modalidade seminário, realizados principalmente no ensino superior. $\mathrm{O}$ professor define um texto para leitura e combina uma data em que o seminário será realizado. Sem um acordo sobre as responsabilidades dos participantes, este tipo de atividade é em geral pouco enriquecedor. Entre os equívocos típicos cometidos nesses encontros, podemos citar: (a) poucos alunos fazem uma leitura cuidadosa do texto, (b) somente alguns participam dos debates, (c) muitos dos que participam emitem suas opiniões particulares sem o apoio fundamentado da leitura. Como em geral são realizados sem registros, ainda que todos estivessem interessados, a conversação, por mais empolgante que seja, ficará perdida e pouca coisa será lembrada para posteriores reflexões.

Muitas dos obstáculos encontrados na escola atual para promover o estabelecimento de diálogos pedagógicos, capazes de favorecer os desequilíbrios necessários à aprendizagem, são resultantes das tecnologias usadas no contexto escolar. Os tempos de aula reduzidos, o suporte individual para registro de anotações, a ausência da tecnologia digital, por certo trazem implicações marcantes, embora não sejam os únicos problemas.

Com a tecnologia digital, podemos repensar o tempo e a distância. Os alunos podem, através de ambientes adequados, prosseguirem as interações longe da sala de 
aula, em horários diferenciados e nos mais diversos locais. O uso dos ambientes digitais pode favorecer novas práticas ou enriquecer as antigas, desde que estas se modifiquem para contemplar uma política apropriada das interlocuções de forma que cada participante se sinta responsável pelo processo de aprender junto e possa participar em tempos e locais diversificados.

Muito se fala da aprendizagem que pode ocorrer nas redes sociais, nos fóruns de discussão e outros, criados livremente pelos indivíduos em uma excelente apropriação que a sociedade vem fazendo das tecnologias digitais. Há que se distinguir, entretanto, a possibilidade de aprender usando estes mecanismos com a concretização desse aprendizado. Em geral, em redes onde isso de fato ocorre, há uma política de participação e um comprometimento dos sujeitos que favorece a construção coletiva de conhecimento. O mero uso de ambientes digitais sofisticados não implica em melhoria das práticas de aprendizagem.

Vejamos um exemplo típico do que pode ocorrer com o uso simplificado das tecnologias. Uma prática corriqueira, no uso de ambientes virtuais, é a transposição dos chamados seminários, em que um artigo é selecionado para leitura e é dado um prazo para debates. Ao invés de um encontro síncrono para realizar os debates, abre-se um fórum em algum suporte na internet e é estabelecido um prazo para que os participantes realizem suas intervenções. Em geral, as intervenções são solitárias (o aluno faz postagens comentando o texto e dá a sua tarefa por cumprida), ou competitivas (querendo fazer valer sua opinião) e/ou descompromissadas (intervenções de apoio, de repúdio, felicitações etc), motivos que tornam essa prática um instrumento pouco eficiente na promoção da aprendizagem.

Aprender em rede requer, além da disponibilidade dos recursos, um interesse dos participantes na realização de diálogos descentrados, buscando a coordenação dos diversos pontos de vista (Piaget, 1998) com o objetivo de fazer emergir um nível melhor qualificado de compreensão da temática em debate. A mera disponibilidade da tecnologia, por mais sofisticada que seja, não basta, é fundamental que se estabeleça uma política de participação e que o grupo tenha interesse na avaliação cooperativa.

No PEAD buscou-se conceber propostas inovadoras a partir do conceito de Arquiteturas Pedagógicas. Na seção seguinte fazemos uma apresentação de algumas dessas propostas experienciadas no contexto da interdisciplina Seminário Integrador.

\section{Arquiteturas Pedagógicas}

O conceito de Arquiteturas Pedagógicas (AP) (Carvalho, Nevado, Menezes, 2005) norteou o desenvolvimento dos materiais utilizados e a elaboração de várias propostas de atividades no contexto de várias interdisciplinas. Nesta seção apresentaremos três arquiteturas que tiveram ampla repercussão na construção da rede de aprendizagem, iniciadas e articuladas a partir de atividades promovidas nos vários polos sob a coordenação do Seminário Integrador.

As Arquiteturas Pedagógicas (AP) são definidas como "suportes estruturantes" para a aprendizagem que combinam epistemologia e concepção pedagógica, com o aparato tecnológico, dentro de uma visão ecossistêmica. A tecnologia não é entendida apenas como um suporte para as ações dos sujeitos, mas sim como elemento que também constitui as novas relações e formas de pensar. A ideia das APs insere-se na perspectiva da ecologia cognitiva (Levy, 1993) já que pressupõe articulações entre sujeitos, artefatos computacionais e ideias pedagógicas que promovem aprendizagens coletivas. 
No PEAD, a partir dos princípios apresentados em (Carvalho, Nevado, Menezes, 2005), as arquiteturas foram elaboradas considerando os seguintes aspectos:

- Resgate do conhecimento prévio dos sujeitos;

- Proposta de exploração ativa;

- Mediações problematizadoras e de suporte às reconstruções;

- Proposta para interações entre sujeitos;

- Suporte Tecnológico que favoreça a construção cooperativa de conhecimento;

- Avaliação Cooperativa.

A seguir apresentam-se três dessas arquiteturas experienciadas no desenvolvimento do PEAD.

\subsection{Debates de Teses}

Buscando caminhos para promover o envolvimento dos participantes a caminho da construção de conhecimento, concebemos e utilizamos no contexto do PEAD uma Arquitetura Pedagógica que denominamos Debate de Teses (Nevado, Menezes, VieiraJr, 2011).

Apesar desta AP admitir inúmeras variações, tomaremos uma dessas possibilidades consideradas no curso.

Para os interesses desta AP entende-se por tese uma proposição qualquer, que pode servir de suporte a uma discussão. Em um debate de teses identificamos as seguintes etapas, cada uma das quais possui um tempo de duração combinando a priori (cronograma):

1. Definição de uma temática;

2. Levantamento de teses com potencial de provocar o surgimento de diferentes interpretações. Uma boa forma de selecionar teses é partir do conhecimento prévio dos alunos sobre o tema a ser debatido.

3. Posicionamento Inicial - quando cada participante deve se posicionar discordando ou concordado com a tese e apresentando para isso uma justificativa fundamentada em evidências (teóricas ou empíricas);

4. Revisão por Pares - quando cada participante é convidado a fazer uma revisão da argumentação dada por dois colegas, para todas as teses. Essa revisão busca perturbar as certezas apresentadas indicando incoerências, falsas argumentações etc;

5. Réplica - quando os argumentadores devem ler os comentários dos revisores e buscar responder, complementando as suas justificativas e/ou questionando baseado em novas evidências, a revisão dos colegas;

6. Posicionamento Final - quando os argumentadores (que também são revisores) são convidados a apresentar um novo posicionamento justificado.

7. Fechamento - quando o professor, após um levantamento das principais convergências e divergência apresenta-as juntamente com seus comentários, apontando onde há posição que estão incompletas e/ou com falta de sustentação nas evidências.

8. Avaliação - durante o transcurso do debate, os participantes registram suas dificuldades, conquistas, insights e evidencias de aprendizagem. Que pode ser consolidada ao final do debate. 
Como todos revisam e são revisados, há a possibilidade concreta de se formar uma rede de interlocuções, a partir da qual as ponderações e divergências podem se propagar. Cada participante se torna um ponto focal em torno do qual existem outros 4 participantes, dois revisores e dois revisados, como ilustrado na Figura 2. O participante 1 revisa as argumentações dos participantes 2 e 3 e tem suas argumentações revisadas pelos participantes 4 e 5 .

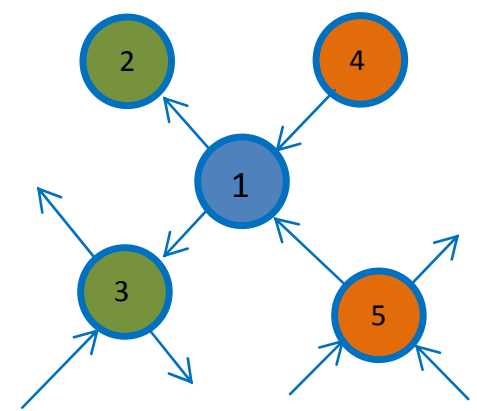

Figura 2 - Um nó da rede de debates, com foco em um dos participantes.

Observe que nesta distribuição um determinado indivíduo vai ler os argumentos sobre o posicionamento de dois colegas, o que significa que além de suas argumentações ele terá contato direto com duas outras maneiras de pensar sobre as teses. Ao mesmo tempo, será revisado por dois colegas, trazendo assim um contato indireto com outras duas maneiras de pensar sobre cada tese.

\subsubsection{Suporte Computacional}

A realização desta atividade foi apoiada por um editor de sites do tipo wiki, disponível gratuitamente na internet, denominado pbworks (http://pbworks.com). Para cada participante foi montada uma página com uma matriz de debate conforme o Quadro 1. $\mathrm{O}$ acesso às páginas de debates é feito a partir de uma página principal, onde estão listados os participantes, juntamente com um link para a sua página de argumentação e para as páginas a serem revisadas por ele.

\section{Quadro 1 - Página de debates de um argumentador}

\begin{tabular}{|c|c|c|c|c|}
\hline \multicolumn{5}{|l|}{ Argumentador } \\
\hline \multicolumn{5}{|l|}{ Revisor 1} \\
\hline \multicolumn{5}{|l|}{ Revisor 2} \\
\hline Teses & $\begin{array}{l}\text { Posicionamento } \\
\text { inicial argumentado }\end{array}$ & Revisões & Réplicas & $\begin{array}{l}\text { Posicionamento } \\
\text { final argumentado }\end{array}$ \\
\hline Tese 1 & & revisão 1 & réplica 1 & \\
\hline \multicolumn{5}{|l|}{ Tese 2} \\
\hline \multicolumn{5}{|l|}{$\ldots$} \\
\hline Tese $n$ & & & & \\
\hline
\end{tabular}


Posteriormente, esta arquitetura foi materializada em um ambiente computacional específico (http://www.lied.inf.ufes.br/debate), com vários ganhos para as atividades de coordenação e acompanhamento do debate, além de automatizar algumas tarefas de preparação (Nevado, Menezes, Vieira-Jr, 2011).

\subsubsection{Sobre o uso da arquitetura}

Esta arquitetura teve um papel fundamental para a apropriação pelos estudantes da ideia de aprendizagem em rede. Nos momentos iniciais, havia uma preocupação exagerada em evitar a crítica aos posicionamentos dos colegas, com medo de prejudicá-los ou de melindrá-los e, por outro lado, o medo de receber críticas.

Houve um esforço intensivo das equipes docentes em ajudar os estudantes a enxergarem as revisões como momento privilegiado de apoiarem os colegas na explicitação de suas posições a partir da crítica e, ao mesmo tempo, buscou-se orientálos para lerem as críticas que lhes fossem feitas como um apoio às suas reflexões e possíveis reformulações.

Ainda que as concepções sobre a ideia da crítica como um suporte à construção do conhecimento não seja algo que se consegue mudar muito rapidamente, acreditamos que a partir de atividades desta natureza podemos contribuir decisivamente para a quebra do medo arraigado pela crítica e proporcionar boas oportunidades para aprenderem a vivenciar contraposições e apreciarem as críticas como contribuições ao enriquecimento das aprendizagens.

\subsection{Projetos de Aprendizagem}

Em Projetos de Aprendizagem (Fagundes, Sato, Maçada, 1999), (Monteiro et all, 2005), (Costa, Magdalena, 2010) os alunos realizaram em grupos uma investigação sobre temas de seus interesses. A escolha dos temas se deu a partir de um levantamento inicial de indagações, que foram posteriormente agrupadas por similaridade. A seguir, os grupos formaram-se a partir das escolhas das questões pelos alunos. Para cada debate foi criado um espaço de trabalho, um site do tipo wiki usando o pbworks. O wiki foi então desdobrado em páginas para os registros das investigações.

O desenvolvimento se realizou em quatro etapas:

Etapa 1: Levantamento do conhecimento prévio. Certezas temporárias e dúvidas provisórias são registradas em um quadro seguido da elaboração de um mapa conceitual;

Etapa 2: Planejamento da investigação. As certezas e dúvidas são agrupadas considerando a possibilidade se serem pesquisadas em conjunto e as fontes de pesquisa eram selecionadas. A definição de tempo e a distribuição da tarefa de coleta de informações também fazem parte dessa etapa;

Etapa 3: Desenvolvimento da investigação. Seguindo o planejamento, as certezas provisórias vão sendo confirmadas ou refutadas a partir do acesso a dados das fontes de informação, os participantes debatem e tiram conclusões. As dúvidas são esclarecidas a partir do acesso a diferentes fontes, que geram debates a partir dos quais os participantes 
tiram suas conclusões. Para cada uma das subetapas de investigação é criada uma página para registros das coletas de informação, dos debates e das conclusões. No pbworks, cada página está associada com um espaço próprio para debate, em forma arborescente. Ao final de cada subetapa os grupos providenciam uma atualização do mapa conceitual que deve ser publicado. Quando necessário um replanejamento é realizando buscando contemplar novas certezas e dúvidas identificadas no percurso. Ao final das subetapas o grupo elabora uma síntese das descobertas, elaborando respostas à questão de investigação.

Etapa 4: Socialização. Ainda que os sites dos grupos estejam continuamente abertos para visitas e contribuição dos colegas dos demais grupos, há um momento especial onde os grupos apresentam oralmente os processos de aprendizagem que realizaram. A partir daí os colegas podem ser designados para fazerem a leitura e revisão do site de outro grupo. A revisão pode ser individual ou por grupo de projeto.

Etapa 5:Avaliação Cooperativa. Com base em indicadores construídos pelo grupo, com a orientação dos mediadores, cada grupo faz uma auto-avaliação. A seguir cada grupo analisa as produções de outro grupo para o qual foram designados. Posteriormente os mediadores analisam as produções de cada grupo, suas auto- avaliações e a avaliação do grupo-revisor, emitindo também o seu parecer.

\subsubsection{Suporte Computacional}

Em termos de ambientes de apoio, observa-se também a formação de uma estrutura de hipertexto, que facilita a navegação. Na Figura 3 ilustra-se a estrutura básica que se constrói no desenvolvimento de Projetos de Aprendizagem. Adicionalmente, outros links são criados entre os próprios projetos, diretos e indiretos em função das visitas individuais. Também é comum a criação dos links externos para referenciar trabalhos e fontes relacionadas com o tema tratado pelo projeto. Cada página pode conter conteúdos em diferentes mídias, tais como imagens, textos e vídeos.

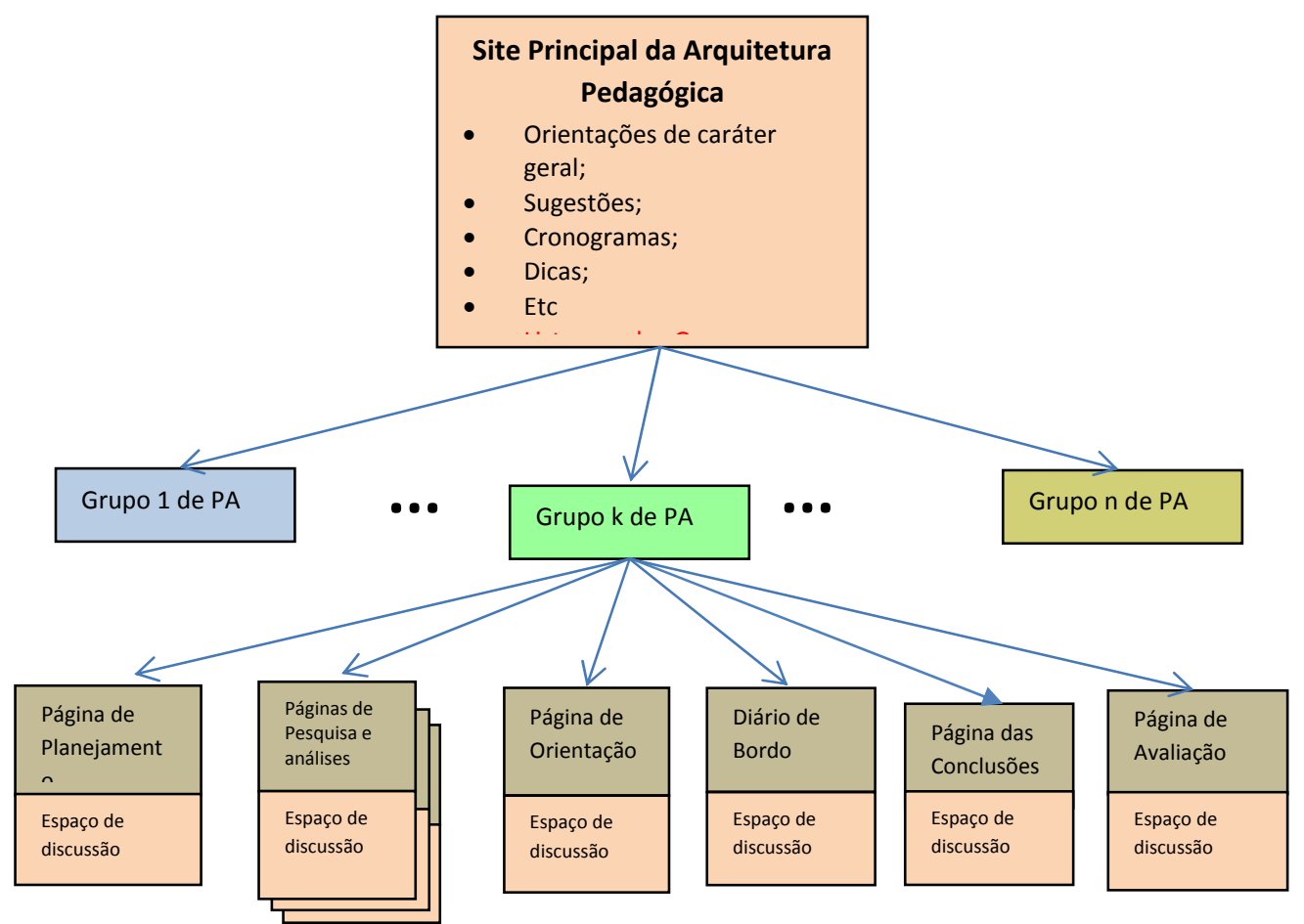


Figura 3 - Esquema de organização do Espaço Digital para o Desenvolvimento de projetos da Aprendizagem, com detalhamento das possíveis páginas de um projeto específico. 


\subsubsection{Sobre o uso da arquitetura}

O que se pode constatar no uso desta arquitetura é a formação de uma rede de aprendizagem, usando a metodologia da investigação, onde todo o processo fica registrado e disponível para leitura dos participantes. As contribuições individuais são identificadas a partir da senha de acesso que é individual. Os debates e as orientações também ficam visíveis, o que permite uma apropriação coletiva de todos os aspectos trabalhados nos projetos.

A abordagem inicialmente provocou grandes desequilíbrios sobre o conceito de ensinar-aprender. Os alunos, que enquanto professores estão acostumados com a tarefa de ensinar, segundo os temas por eles designados, ficaram desconfiados com a proposta na qual o professor deve apoiar as aprendizagens dos alunos organizados em grupos de estudos, onde cada grupo deveria discutir um tema. O trabalho continuado dos docentes do Seminário Integrador foi aos poucos contribuindo para perceberem que existem papéis mais interessantes para os professores do que a tarefa de explicar novos conteúdos. Foi assim também que conseguiram perceber que estudando o assunto que lhes interessa os alunos ficam mais mobilizados e com isso realizam aprendizagens de melhor qualidade. Em consequência desta apropriação vários alunos se envolveram em transposição didática e aplicaram esta arquitetura durante o estágio curricular e na sequência desenvolveram seus TCCs analisando os resultados da aplicação dos PA com seus alunos.

\subsection{Portfólio de Aprendizagens}

A avaliação do curso, assunto introduzido na seção 2, foi processual, o que demandou acompanhamento e orientação ao longo de cada semestre e por todos eles. Esta atividade foi orientada, supervisionada e acompanhada pela equipe do Seminário Integrador (SI) e dos tutores de Polo. Participaram ainda desta construção todos os demais tutores e professores das diversas interdisciplinas.

A sistematização se deu através de uma Arquitetura Pedagógica que teve como atividade estruturante o registro realizado por cada aluno sobre as suas aprendizagens. Cada aprendizagem relevante para o aluno deveria ser alvo de uma postagem. $\mathrm{O}$ contexto da aprendizagem poderia ser o desenvolvimento de uma atividade desenvolvida em outra interdisciplina, uma atividade independente realizada pelo aluno em própria atividade docente, planejando aulas ou trabalhando com seus alunos, ou mesmo as atividades cotidianas. Duas coisas eram requeridas nestas postagens: (a) que a descrição tivesse uma estrutura baseada em evidências e argumentações e (b) que se estabelecessem conexões com as temáticas das interdisciplinas do curso e com outras que julgassem importantes para caracterizar as suas aprendizagens. As conexões eram registradas pela indicação de uma ou mais tags associadas com um registro. Era recomendado a cada aluno que buscasse realizar o registro de pelo menos duas postagens semanais. Para acompanhar estas atividades os tutores mantinham um registro individual de postagens que era compartilhado com os alunos.

Os professores e tutores do SI acompanharam estes registros um por um, com diferentes focos de interesse. O foco mais básico era a revisão da estrutura das postagens, apoiada em argumentos e evidências, favorecendo com isso a construção de textos mais esclarecedores. Um segundo foco era o acompanhamento da cobertura do conteúdo das postagens com respeito às diversas interdisciplinas do curso. A equipe do SI mantinha um registro por aluno da quantidade de postagens relacionadas com as 
demais interdisciplinas oferecidas em um dado semestre, para que os demais professores e tutores pudessem acompanhar as aprendizagens percebidas. Quando uma formulação apresentada requeria um olhar especial de uma determinada equipe de interdisciplina a equipe do SI notificava as outras equipes envolvidas. Com isso, aconteciam novos comentários para determinadas postagens. Usando o método clínico piagetiano (Delval, 2002), o corpo docente oferecia elementos para que o aluno ampliasse a sua compreensão sobre o que estivesse relatando. Conforme explicita Delval (2002), a partir do método clínico é possível "[...] acompanhar o curso do pensamento do sujeito ao longo da situação, fazendo sempre novas perguntas para esclarecer respostas anteriores” (p. 12). Segue esclarecendo que "o pesquisador [ou, no caso do curso, professor e/ou tutor] mediante suas ações ou suas perguntas, procura compreender melhor a maneira como o sujeito representa a situação e organiza sua ação” (Delval, 2002, p. 12).

Todos os registros e comentários ficaram disponíveis para que, além dos tutores e professores, os demais alunos pudessem acompanhar, opinar, contribuir, referenciar e qualquer outro tipo intervenção que julgassem apropriada.

Com base nestes registros e apoiados em questionamentos levantados pelo corpo docente de cada eixo, os alunos elaboravam ao final de cada semestre um documento de avaliação, síntese de suas aprendizagens, que dava suporte a uma sessão de apresentação oral para uma banca avaliadora.

No início de cada semestre era solicitado aos alunos que fizessem uma postagem adicional, em seu portfólio, fazendo uma síntese das aprendizagens do semestre anterior, considerando as aprendizagens que elegessem representativas do seu desenvolvimento.

Durante a realização do nono semestre do curso, quando os alunos realizavam os estudos que culminaria com a produção do Trabalho de Conclusão de Curso (TCC) foi proposta uma variação da arquitetura. A atividade estruturante consistiu na postagem de reflexões baseadas em uma revisita aos registros dos semestres anteriores, para cada um dos quais foi solicitado que fizessem uma ou mais postagens, tentando estabelecer ligações entre o que estudaram em um dado semestre e suas conexões com o prosseguimento do curso. O objetivo principal era proporcionar aos alunos a oportunidade de fazerem uma avaliação integrada das aprendizagens individuais em estreita conexão com o desenvolvimento do curso.

\subsubsection{Suporte Computacional}

A busca por um suporte de uso fácil e ao mesmo tempo sofisticado o suficiente para contemplar os requisitos da Arquitetura, encaminhou-nos para a escolha de uma ferramenta que oferecesse suporte à colaboração estruturada, baseada nas autorias diferenciadas, separando os participantes em autores e colaboradores. Para cada aluno foi criado um blog individual, visando as suas postagens "obrigatórias”. Os professores, os tutores e os demais colegas, realizaram suas intervenções usando o suporte a comentários da ferramenta.

A disponibilidade de serviços gratuitos de blog com um alto nível de disponibilidade e acesso de boa qualidade, associados à simplicidade por certo contribuíram para o sucesso da implementação desta arquitetura.

\subsubsection{Sobre o uso da arquitetura}

Na concepção do PEAD está explicitamente destacada a importância de se buscar uma formação que rompesse com as propostas convencionais de atividades focadas no 
cumprimento de tarefas, além de fomentar a relação teoria-prática. A atividade apresentada por esta arquitetura contribuiu de modo decisivo para que estes objetivos fossem articulados durante todos os momentos da realização do curso. As propostas percorreram todo o curso, sem se caracterizar como cumprimento de tarefas. Em alguns instantes, aconteceram tensionamentos, originados pela preocupação dos alunos em conviver com uma atividade de tão longa duração. $\mathrm{O}$ fato de que suas postagens fossem revisadas e a elas fossem sugeridas modificações, trouxe certo sentimento de algo inacabado, como de fato deveria ser. A conclusão de uma atividade não era o foco da proposta, cada postagem era o ponto de partida para um diálogo visando novos aprofundamentos. A arquitetura teve um papel relevante para que os alunos pudessem compreender a aprendizagem como um processo continuado de reconstrução.

\section{Considerações Finais}

A oferta de um ambiente de trabalho flexível, ajustado às necessidades de cada proposta pedagógica (Arquiteturas) mostrou-se adequado ao desenvolvimento das aprendizagens conforme se pôde constatar posteriormente em um levantamento sobre a satisfação dos alunos, onde as propostas pedagógicas, os ambientes flexíveis e a mediação das interações se destacaram como elementos fundamentais (Nevado, Menezes, 2012).

No sétimo semestre do curso foi realizada uma coleta de dados junto aos alunos, buscando avaliar o modelo do curso. Entre as questões abertas, solicitou-se aos alunos que indicassem três características facilitadoras das aprendizagens. A questão foi respondida por 230 alunas (70\% dos alunos ativos) num total de 691 indicações. Destes dados, obtivemos alguns agrupamentos. Na Tabela 1 apresentamos as indicações relacionadas com o suporte à interação/comunicação.

Tabela 1 - Características facilitadoras: interações/comunicação

\begin{tabular}{l|c}
\hline \multicolumn{1}{c|}{ Características } & $\mathbf{N}$ \\
\hline $\begin{array}{l}\text { Trabalhar em rede de interações virtuais, parceria, cooperação, ajuda } \\
\text { mútua (professores. Tutores, colegas) }\end{array}$ & 52 \\
\hline $\begin{array}{l}\text { Oferecer retornos com agilidade e qualidade, dando oportunidade } \\
\text { para o aluno refazer atividades }\end{array}$ & 30 \\
\hline Promover a interação, debates usando tecnologia (online e offline) & 26 \\
\hline $\begin{array}{l}\text { Propor trabalhos cooperativos, trocas com colegas, trabalhos em } \\
\text { grupo }\end{array}$ & 25 \\
\hline Total & $\mathbf{1 3 3}$ \\
\hline
\end{tabular}

Fonte: (Nevado, Menezes, 2012)

Na Tabela 2 apresentamos as indicações relacionadas com os materiais pedagógicos e as tecnologias.

Tabela 2 - Características facilitadoras: materiais pedagógicos e tecnologias

\begin{tabular}{l|c}
\hline \multicolumn{1}{c|}{ Características } & N \\
\hline $\begin{array}{l}\text { Qualidade dos materiais e propostas pedagógicos, de fácil acesso e } \\
\text { entendimento, atualização. }\end{array}$ & 40 \\
\hline Bom apoio de literatura, bibliografia, vídeos, filmes. & 39 \\
\hline $\begin{array}{l}\text { Apropriação tecnológica, uso das TICs nas atividades, TICs } \\
\text { diversificadas. }\end{array}$ & 36 \\
\hline
\end{tabular}


Acesso fácil aos materiais pedagógicos e informações de qualidade

\begin{tabular}{l|l}
\hline Total & 134 \\
\hline
\end{tabular}

Fonte: (Nevado, Menezes, 2012)

As concepções anteriores dos cursistas, baseados em uma abordagem de formação convencional, foram aos poucos cedendo espaço para o surgimento de uma nova concepção de formação de professores, o professor-pesquisador. Aquele para o qual cada desequilíbrio provocado por suas turmas, é ponto de partida para a busca de explicações, que levam a novas leituras e novos experimentos.

A atuação intensiva dos tutores, empenhados em oferecer a crítica desequilibradora e o posterior suporte à reconstrução, exercitados ao longo de toda a trajetória dos alunos, deu surgimento a uma parceria baseada na confiança, que contribuiu decisivamente para a criação da rede de aprendizagem e para a formação de um professor responsável por sua formação continuada e pelos destinos de suas salas de aula.

\section{Referências Bibliográficas}

Becker, F. (2001), Educação e Construção de Conhecimento. Artmed, Porto Alegre RS.

Carvalho, M. J. S., Nevado, R. A., Bordas, M. C. (2006) Licenciatura em Pedagogia a Distância: Anos Iniciais do Ensino Fundamental - Guia do Tutor - Porto Alegre.

Carvalho, M. J. S., Nevado, R. A., Menezes, M. C. (2005) Arquiteturas Pedagógicas para Educação a Distância: Concepções e Suporte Telemático, Anais do SBIE, Juiz de Fora - MG.

Costa, I.E.T., Magdalena, B.C.(2010), Revisitando os Projetos de Aprendizagem, em tempos de web 2.0, Anais do SBIE, Fortaleza - CE.

Delval, J. (2002). Introdução à prática do método clínico. Porto Alegre: Artmed.

Fagundes, L. C., Sato, L.S., Maçada, D.L.(1999), Aprendizes do futuro: as inovações começaram. Coleção Informática para a mudança na Educação. Brasília: MEC/SEED/ProInfo.

Freire, Paulo (1996), Pedagogia da autonomia: saberes necessários à prática educativa. São Paulo: Paz e Terra, (coleção leitura)

Freire, P., Faundez, A. (1985) Por uma Pedagogia da Pergunta. Editora Paz e Terra, São Paulo - SP - Brasil.

Lévy, Pierre (1993), As Tecnologias da Inteligência: O Futuro do Pensamento na Era da Informática, São Paulo - SP, Editora 34.

Monteiro, V. C. P. C. ; Menezes, C. S. ; Nevado, R. A. ; Fagundes, L. C. (2005) . Ferramenta de Autoria e Interação para apoio ao desenvolvimento de Projetos de Aprendizagem. RENOTE. Revista Novas Tecnologias na Educação, Porto Alegre - RS, v. vol 3, n. no. 2. 
Nevado, R.A., Menezes, C.S., Vieira-Jr, R.R.M. (2011), Debate de Teses - Uma Arquitetura Pedagógica, SBIE - Simpósio Brasileiro de Informática na Educação, Aracaju - SE.

Nevado, R.A., Menezes, C.S. (2012), Pressupostos, intenções e práticas de um curso a distância: as contribuições das percepções dos alunos para a avaliação do modelo, Revista Perspectiva, vol. 30, n. 1, Florianópolis.

Piaget, J. (1998). Observações psicológicas sobre o trabalho em grupo. In: Parrat, S.; Tryphon, A. Sobre a pedagogia: textos inéditos. São Paulo: Casa do Psicólogo.

Piaget, J. (1973), Problemas de Psicologia Genética. Rio de Janeiro: Forense. 